\title{
Investigation of the excitation functions for some medical radioisotopes production
}

\author{
Fatma K1lınç ${ }^{1, a}$, Nurdan Karpuz ${ }^{2}$,and Betül Çetin ${ }^{1}$ \\ ${ }^{1}$ Amasya University, Department of Physics, Amasya, Turkey \\ ${ }^{2}$ Amasya University, Sabuncuoğlu Şerefeddin Health Services Vocational School, Amasya, Turkey
}

\begin{abstract}
One of the main application fields of nuclear technology is medicine and radioisotopes are used in medicine. Production of those radioisotopes is important and in the production processes the cross section must be known. All the production of radioisotope used in medicine is based on the nuclear reactions means they are not natural. The decay time of produced radioisotopes is important as from production to hospital can take time and thus generally generator is used to produce some radioisotopes. Radioisotopes are widely produced in reactors or cyclotron type accelerator. Type of radioisotopes direct way to be used in production processes. Thus obtaining of cross section becomes crucial. For this purposes the theoretical calculation cross section of some radioisotopes used in medicine will be calculated in this study. The calculations will be done using Monte Carlo code of TALYS 1.6
\end{abstract}

\section{Introduction}

Nuclear physics, in the sense of the emergence of important technological innovation is a field of Science. Nowadays, it has a wide usage. These areas, which is one of nuclear medicine, are used for both diagnostic and treatment purposes and helps in diagnosis. Radionuclide generators can be produced with the desired properties by means of radioisotopes for diagnosis and treatment. If we look in terms of nuclear reactions the obtained experimental results important for the understanding of basic nuclear physics.

Energy of nuclear reactions energy dependence of the cross section and the spectral value is not known in detail for as numerous of delivery must be examined. Radioisotopes produced in reactors typically have short half-lived. The spectra of these nuclei cross-section and delivery is unlikely to be measured directly. In this sense, in terms of gaining time, we must do this first, theoretical nuclear reaction cross sections it is necessary to calculate in advance.

Experimental measurements of long-term, costly and does not occur at the same energy for different isotopes. Understanding the mechanisms of experimental and theoretical reaction cross section, there is a need to develop models to be used to. At the same time, verification of the theoretical model and the empirical formula of the studies, in order to create the experimental data is referenced. On the other hand, with the theoretical cross section predictions obtained with the nuclear models successful and scientifically verified data, may correct a deficiency that cannot be obtained in the experimental way. In this case, both experimental and theoretical studies of the cross section, there is a significant need in this area. In addition, the obtained nuclear data, nuclear structure and nuclear models for the investigation of theoretical studies has an important place in the development. [1].

\section{Methods}

${ }^{13} \mathrm{~N},{ }^{18} \mathrm{~F}$ are the radioisotopes used in nuclear medicine. Besides, ${ }^{12} \mathrm{C},{ }^{20} \mathrm{Ne},{ }^{16}$ Oisotopes used in a medical sense, ${ }^{13} \mathrm{~N},{ }^{18} \mathrm{~F}$ is used as target material for the production of radioisotopes. These radioisotopes are used in research on the brain.

In this study, the cross section of ${ }^{12} \mathrm{C}(\mathrm{d}, \mathrm{n}),{ }^{20} \mathrm{Ne}(\mathrm{d}, \alpha)$, ${ }^{16} \mathrm{O}\left({ }^{3} \mathrm{He}, \mathrm{p}\right)$ reactions was calculated. The calculations, it was theoretically with Talys 1.6 program by Monte Carlo simulation code for nuclear reaction. TALYS is a nuclear reaction simulation computer code system for the analysis and prediction of nuclear reactions. Talys 1.6 [2] program $1 \mathrm{keV}-1 \mathrm{GeV}$ in the energy range of the proton, neutrons, deuteron, triton, gamma, alpha and ${ }^{3} \mathrm{He}$ particles with a mass of 12 and more, which examines the interaction of the core. TALYS nuclear reaction simulation programme to make predictions about how you can achieve results with different models for reaction cross section offers the possibility. The program has two main objectives. Firstly, experiments in the theoretically of nuclear reactions can be performed. Secondly, the nuclear data tool is needed. It has the FORTRAN programming language. Runs on Linux operating system.

\footnotetext{
${ }^{\mathrm{a}}$ Corresponding author: fkilinc27@hotmail.com
} 


\subsection{Figures}

The calculated ${ }^{12} \mathrm{C}(\mathrm{d}, \mathrm{n}),{ }^{20} \mathrm{Ne}(\mathrm{d}, \alpha),{ }^{16} \mathrm{O}\left({ }^{3} \mathrm{He}, \mathrm{p}\right)$ reaction cross sections have been displayed in Figs. 1, 2 and 3.

The obtained results have been compared with the experimental data existing in the EXFOR [3] databases.

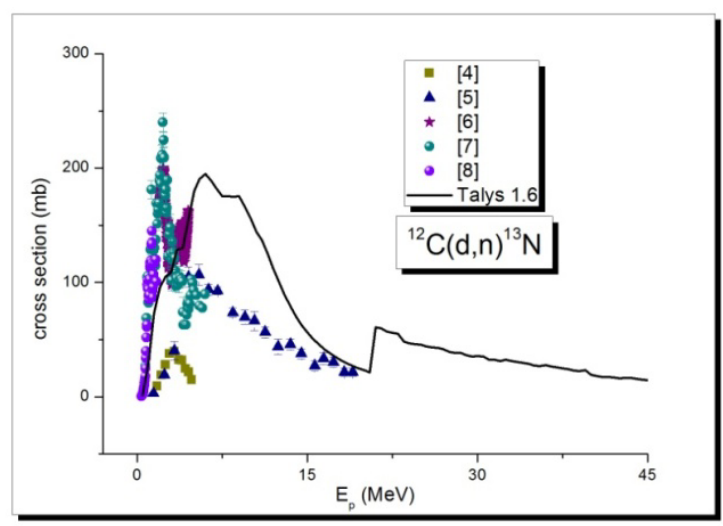

Fig. 1. The calculated cross sections of ${ }^{12} \mathrm{C}(\mathrm{d}, \mathrm{n})$ reaction and comparison with experimental results.

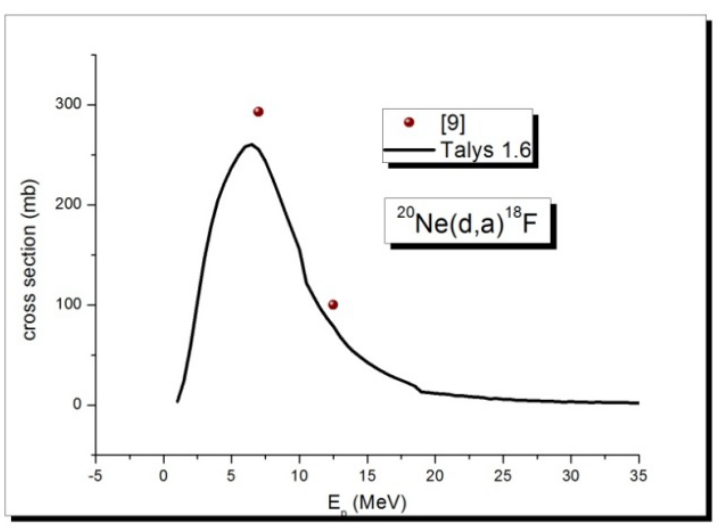

Fig. 2. The calculated cross sections of ${ }^{20} \mathrm{Ne}(\mathrm{d}, \alpha)$ reaction and comparison with experimental results.

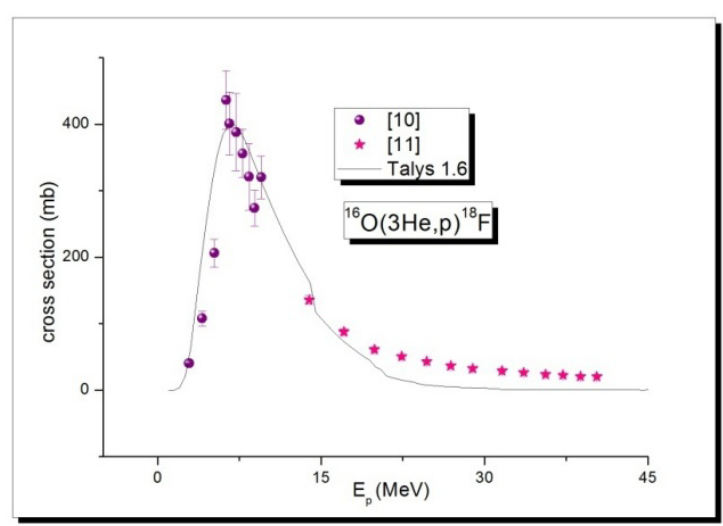

Fig 3. The calculated cross sections of ${ }^{16} \mathrm{O}\left({ }^{3} \mathrm{He}, \mathrm{p}\right)$ reaction and comparison with experimental results.

\section{Conclusion}

In this work, ${ }^{12} \mathrm{C}(\mathrm{d}, \mathrm{n}),{ }^{20} \mathrm{Ne}(\mathrm{d}, \alpha),{ }^{16} \mathrm{O}\left({ }^{3} \mathrm{He}, \mathrm{p}\right)$ reaction cross section values for the reaction were calculated in the energy range between 0.5 and $100 \mathrm{MeV}$. Our results are in fair agreement with both, available experimental data in literature. The maximum cross section values are $194.913 \mathrm{mb}$ at $6 \mathrm{MeV}$ at the ${ }^{12} \mathrm{C}(\mathrm{d}, \mathrm{n})$ nuclear reaction and $260.383 \mathrm{mb}$ at $6.5 \mathrm{MeV}$ at the ${ }^{20} \mathrm{Ne}(\mathrm{d}, \alpha)$ and 399.559 $\mathrm{mb}$ at $7 \mathrm{MeV}$ at the ${ }^{16} \mathrm{O}\left({ }^{3} \mathrm{He}, \mathrm{p}\right) .{ }^{13} \mathrm{~N}$ is the most appropriate production range; for ${ }^{12} \mathrm{C}(\mathrm{d}, \mathrm{n})$ nuclear reaction is seen that the energy range $5-7 \mathrm{MeV} .{ }^{18} \mathrm{~F}$ is the most appropriate production range; for ${ }^{20} \mathrm{Ne}(\mathrm{d}, \alpha)$ In nuclear reaction is seen that the energy range 5.5-7.5 $\mathrm{MeV} .{ }^{18} \mathrm{~F}$ is the most appropriate production range; for ${ }^{16} \mathrm{O}\left({ }^{3} \mathrm{He}, \mathrm{p}\right)$ nuclear reaction is seen that the energy range 6-8 MeV.

Nuclear medicine radioisotopes for production the necessary reaction cross sections were calculated theoretically. The calculated results were compared with the results of experimental data take from literature. As we can understand from the chart, it is seen that the compatible the experimental data taken from literature with the theoretical results calculated using the Talys1.6 program. The findings in this study; it can be evaluated for model the creation of the experimental studies, nuclear reaction cross section calculations, strengthening of data base needed for radioisotope production programs, creation of a new data base, production technology development.

This study contains thesis results of Amasya University Science Faculty master degree.

\section{References}

1. V. Çapal1., et al., SDU Journal of Science (EJournal), 9 (2), 107-112, (2014).

2. A. Koning, S. Hilaire, S. Goriely, TALYS-1.6 A Nuclear Reaction Program, User Manual (NRG, The Netherlands) (2013).

3. EXFOR/CSISRS, Experimental Nuclear Reaction Data File, Brookhaven National Laboratory, National Nuclear Data Center (2009).

4. H.W. Newson., Physical Review,51620, (1937).

5. O.D. Brill, L.V. Sumin., Atomnaya Energiya, 7377, (1959).

6. R.J. Jaszczak, R.L. Macklin, J.H. Gibbons, Physical Review, 181 ,1428 (1969).

7. R.W. Michelmann, et al., Nucl. Instrum. Methods in Physics Res., Sect. B, 51, 1 (1990).

8. I.Ya. Barit, L.E. Kuzmin, A.M. Kazantsev, Journal of Radioanalytical and Nuclear Chemistry, 97, 97 (1986).

9. M. Guillaume, Nuclear Instrum. and Methods in Physics Res, 136, 185 (1976).

10. R.L. Hahn, E. Ricci, Physical Review, 146650 (1966).

11. J. Fitschen, et al., Applied Radiation and Isotopes, 28, 781 (1977). 